\title{
mijnKOOL, \\ Organic Photography as a Participatory Design Method
}

\author{
Kristof Vrancken \\ Inter-Actions \\ Re-Visionary \\ Luca School of Arts \\ C-Mine 5 \\ 3500 Genk \\ Belgium \\ kristof.vrancken@luca.be
}

\begin{abstract}
mijnKOOL is an artistic participatory research project in which photographer Kristof Vrancken and design studio SOCIAL MATTER actively and naturally examined the Genk soil quality and composition using red cabbage and an organic photographic process. For this, we invited 12 Genk residents to plant a red cabbage in their garden and bring them together to let them experience the unique properties and forces containing plants.
\end{abstract}

Plants can play an important role in detecting soil structures and properties. Red cabbage works well as a bio-indicator. During several meetings we discussed the growth of the cabbages examined soil samples.

The participants created a photographic emulsion of their crop with the anthotype process, which resulted in an image. Depending on the acidity and composition of the soil in which the cabbage did grown changed the colour quality of the print. The use of red cabbage as a measuring instrument for soil composition gives an understanding of the impact that soil may have on ecology and food-production.

For the participatory design conference I want to display the results of the project in an open atelier - lab, and to launch a similar project in the public space of Hasselt. The participants of the conference are invited to join the experiments and to think about future scenarios of this methodology.

\section{CCS CONCEPTS}

- Social and professional topics $\rightarrow$ Sustainability

- Participatory design

KEYWORDS

“photography”, “anthotype”, “cabbage”, “soil”, “ecology”, “bioindicator”, "sustainist design”, "nature”, “artistic research”, "sustainability”, "organic photography”

\section{ACM Reference format:}

Permission to make digital or hard copies of all or part of this work for personal or classroom use is granted without fee provided that copies are not made or distributed for profit or commercial advantage and that copies bear this notice and the full citation on the first page. Copyrights for components of this work owned by others than ACM must be honored. Abstracting with credit is permitted. To copy otherwise, or republish, to post on servers or to redistribute to lists, requires prior specific permission and/or a fee. Request permissions from Permissions@acm.org. PDC '18, August 20-24, 2018, Hasselt and Genk, Belgium (C) 2018 Association for Computing Machinery. ACM ISBN 978-1-4503-55742/18/08...\$15.00 https://doi.org/10.1145/3210604.3214364

\section{INTRODUCTION}

In my artistic research project 'The sustainist gaze', I examine the link between photography and Sustainist Design. [1]. The latter is a movement that argues in favour of design processes with a focus on ecology, innovation, craftsmanship and sustainability within a strong social context.

In Sustainist Design Guide (2013) Schwarz and Krabbendam define four pillars for sustainable design. Sharing is the first pillar. Exchanging knowledge, materials, and tools both online and offline - also known as the open source approach - instead of hiding them leads to greater efficiency in development and production. The second pillar, Localism, stands for returning to and upgrading the local. Think global, Act local refers to the mix between local and global in our environments and experiences today. Our focus should be locally rooted but globally connected. The third pillar Connectedness exceeds the principle of sharing in development and manufacturing. It underlines to the importance of offline and online interpersonal contact. This pillar also refers to the connection with nature and argues in favour of restoring our bond with it. Finally, Proportionality stands for bringing production into balance and custom designing to suit the social and local context. Proportionality also incorporates the aspect of time. In a world in which everything must go faster, it is a relief to 
build in slowness. By daring to stand still, there is more time to discover and to reflect. Sustainist design no longer designs for a society; it starts a new movement from within. I want to contribute to this call in a non-conventional, visual manner. To shape the vital transformation to a sustainable world, we need new streams of thought and design processes as well as a new visual language in order to understand, document, and spread them. After all, images enable us to evaluate critically, to crystallize ideas, to inspire others, and to encourage co-creation. Regarding photography from this perspective made me to return to ecological and traditionally analogue processes that were at the root of the discovery of photography.

One of these processes is the anthotype described by Sir John Herschel in 1842. It is an organic process that affects the discoloration of natural pigments exposed to UV light. An anthotype is created by applying a photosensitive emulsion made from the colour pigments of plants, berries and flowers to a and exposing it to sunlight for several days or weeks. The plant juice undergoes a chemical change during this process and becomes darker or lighter. [2] The Anthotype process proved in my research to be an excellent tool to widen up photography as a participatory design method and to make complex problems visual.

\section{2 mijnKOOL}

mijnKOOL is an artistic participatory research project in which I and design studio Social Matter actively examined the Genk soil quality and composition using red cabbage (Fig. 1). The title of this participatory project alludes, on the one hand, to red cabbage plants that participants grew in their own gardens (translation from the Dutch 'My cabbage'). On the other hand, it alludes to Genk's industrial past via the words 'mine' and 'coal'. By adopting the anthotype process as a participatory research method we intended to bring people together through open communication, and to raise awareness about the unbalanced human-nature ratio.

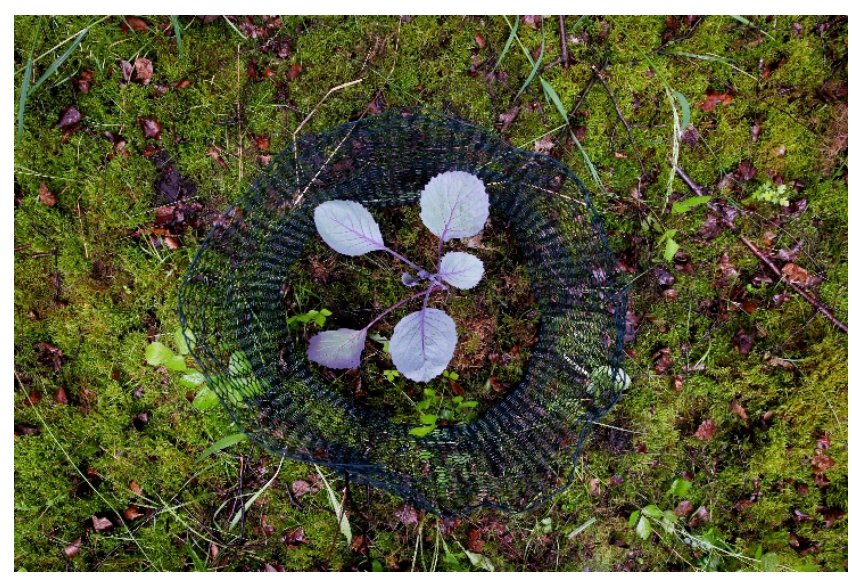

Figure 1: Red cabbage plant as a research tool to examine soil quality in Genk.
The anthotype technique was effectively used as a call for action as inhabitants of Genk were informed via workshops about the potential uses of plants to investigate soil quality. They were directly addressed because they and their habitat were implemented and united in the photographic process and the final image. This participatory method provided a strong local context as well as a wider reach. The project not only connected the usual photography and culture enthusiasts, but also engaged the network of participants. Combining knowledge and strategies from exact sciences, social design and photography in a transdisciplinary project thus created new possibilities to inform and activate people and embedded the project in the local community.

Research shows that some plants are excellent receptors and collectors of heavy metals and fine dust, and that anomalies in growth and flowering of certain plants in a certain area could be an indicator for pollution. Therefore, they are extremely suitable as research tools. Thanks to its anthocyanins, red cabbage could function as a bio-indicator. [3] If it is grown in pure soil, it will turn out more blue and in alkaline environments, it will turn more green and yellow. If the red cabbage is grown in acidic soil, it will yield a red colour. I carried out two experiments to test this method in May 2016 and 2017. A dozen cabbage plants were planted in contaminated and uncontaminated areas in Genk, and in pure potting soil.

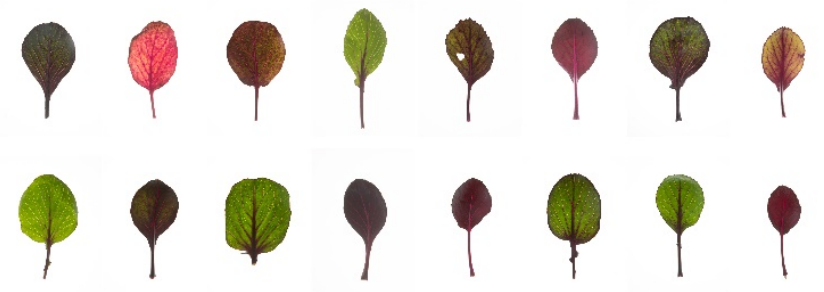

Figure 2: Anomalies in growth and stress symptoms of red cabbage plants in Genk, 2017

Four months later the cabbage pants were harvested and documented. Although some plants had trouble surviving due to the city's poor subsoils, shortage of rain, and damage from caterpillars and slugs, there was enough basic material to carry out a pH-test. This resulted in clearly perceptible colour differences in the final liquids varying from light to dark blue and from light to dark purple. The diverse colours in the test tubes show that red cabbage really does react to the $\mathrm{pH}$-value and soil quality of the subsoil in which it grows. The plants themselves also showed great differences in their growth and leaf structure. The cabbage plants from the polluted industrial areas showed clear stress symptoms and necrosis in their leaves (Fig. 2). Further scientific research, however, will have to show the level of concentrations of heavy metals that actually nests within the photographic emulsions made from the red cabbages and in the final image. 
Every participant in the mijnKOOL-workshop received a red cabbage plant grown in pure compost and was asked to plant it in his/her garden. After a few months, the group came together again and brought their harvest. The participants used their plants to make an anthotype image of the planting area and their portrait image that I made during a workshop.

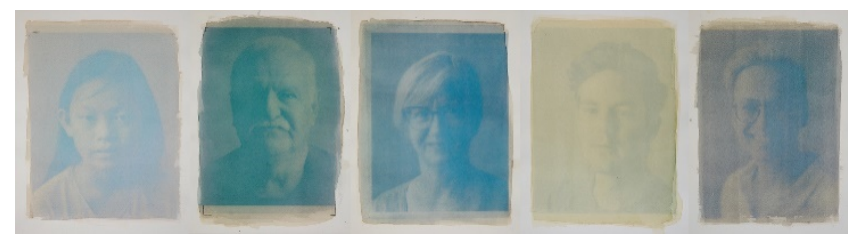

Figure 3: Anthotype portraits of the mijnKOOL participants with the emulsion of the cabbages that were grown in their gardens.

Depending on the acidity of the soil in which the cabbage was grown, the prints clearly had different colours, bringing forth a participative sample card of the Genk surface - and thanks to the anthotype process - of the subsurface as well. Red cabbages that were planted in areas of known pollution were considered in the investigation as well. With these results, we made a visual mapping of the diversity of the soil (Fig.4). The Anthotype process proved to be an appropriate tool to visually translate the urgency of ecology and soil quality.

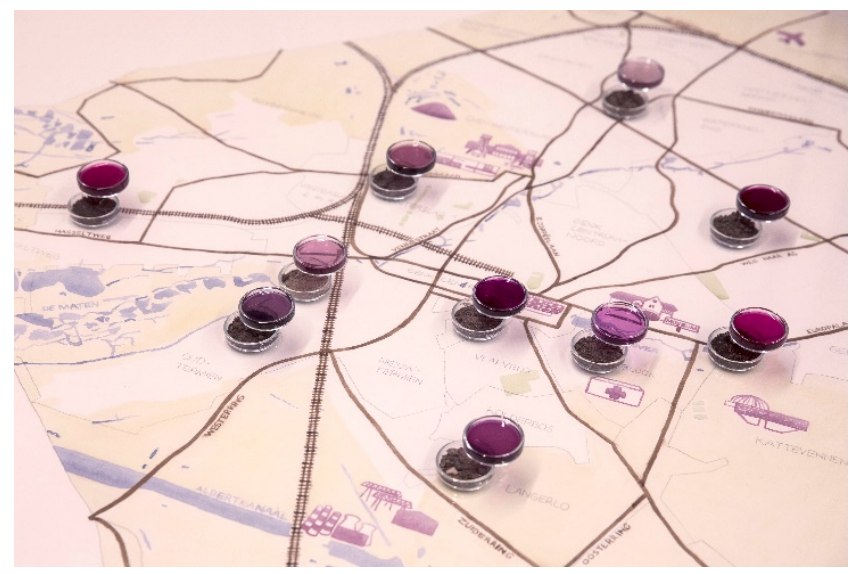

Figure 4: A visual mapping of the soil diversity in Genk with the red cabbage emulsions.

\section{A SITUATED ACTION}

After finishing this Genk case, I would like to apply this methodology to the city of Hasselt to investigate the influence of heavy traffic air pollution on food production in the city.

A team of volunteers will plant and harvest the red cabbages around the city's heavy traffic axes and in the city centre. The results of these projects will be shown in an open atelier - lab during the PDC-conference.
Participants of the conference are invited to participate in experiments about the anthotype process via 30-minute workshops. During this workshop they learn how to extract the colour of the cabbage to make an photographic emulsion and to create a visual map of the city and its soil diversity.

Furthermore, a discussion will be held on the results and how this participatory project can increase its agency and how it can be used to make cities more livable.

\section{CONCLUSION}

Following the call for action, formulated by the sustainist design movement that looks for alternative design and manufacturing processes, and that focuses on the values of sharing, localism, connectedness, and proportionality, I want to make the problem of ecology and soil quality visible and contribute to a greater consciousness of the problematic state of our planet [4-6] by using the nineteenth-century anthotype technique as a participative research method, citizen science and artistic photography. Planting, harvesting, documenting and analysing red cabbage plants becomes a political act.

\section{REFERENCES}

[1] Michiel Schwarz and Diana Krabbendam, Sustainist Design Guide: How Sharing, Localism, Connectedness and Proportionality are creating a New Agenda for Social Design (Amsterdam: BIS Publishers, 2013), 33-47.

[2] John Herschel, "On the Action of the Rays of the Solar Spectrum on Vegetable Colours, and on Some New Photographic Processes,” Philosophical Transactions of the Royal Society of London 132 (1842), 181214.

[3] Linda Chalker-Scott, "Environmental Significance of Anthocyanins in Plant Stress Responses,” Photochemistry and Photobiology 70,1 (1999), 1-9; Marzena Szczygłowska, Anna Piekarska, Piotr Konieczka et al., "Use of Brassica Plants in the Phytoremediation and Biofumigation Processes," International Journal of Molecular Sciences 12,11 (2011), 7760-71.

[4] Christophe Bonneuil and Jean-Baptiste Fressoz, The Shock of the Anthropocene: The Earth, History and Us, trans. David Fernbach (London: Verso, 2017), 289.

[5] Jason W. Moore, Anthropocene or Capitalocene? Nature, History, and the Crisis of Capitalism (Oakland, CA: PM Press/Kairos, 2016).

[6] Socrates Schouten, De circulaire economie. Waarom productie, consumptie en groei fundamenteel anders moeten (Amsterdam: Leesmagazijn, 2016).

\section{MORE INFORMATION}

Blog: http://www.mijnkool.be Video: https://www.youtube.com/watch?v=ODbatFspAPM\&t=4s 